\title{
THE ERODIBILITY OF GRASSED INNER DIKE SLOPES AGAINST WAVE OVERTOPPING
}

\author{
Gijs Hoffmans ${ }^{1}$, Gert Jan Akkerman ${ }^{2}$, Henk Verheij ${ }^{1,3}$, Andre van \\ Hoven $^{1}$ and Jentsje van der Meer ${ }^{4}$
}

\begin{abstract}
This study investigates the erodibility against wave overtopping of clay and grass using vertical forces acting upon a turf-element model. The load is modelled by a lift force caused by pressure fluctuations and the strength by the self-weight, cohesion, shear and root forces. Besides the proposed turf-element model, a failure model for grass based on scour equations has also been developed.
\end{abstract}

\section{INTRODUCTION}

Dutch river dikes, the core material of which usually consists of clay are covered by grass on both the inner and outer slopes. Sea dikes with hard revetments in the wave impact zone of the seaward slope also have a grass cover on the crest and the inner slope. The grass cover includes grassland vegetation rooted in soil, where two layers can be distinguished: the top soil and the subsoil (Fig. 1, Muijs 1999). The porous turf has a high root density and is elastic in moist conditions. The root structure holds the small clay aggregates together and prevents them from being washed out, whereas the underlying substrate, is stiff or plastic and less permeable. For clay, relatively large forces are necessary to break the aggregates, while relatively small forces are necessary to transport the aggregates.

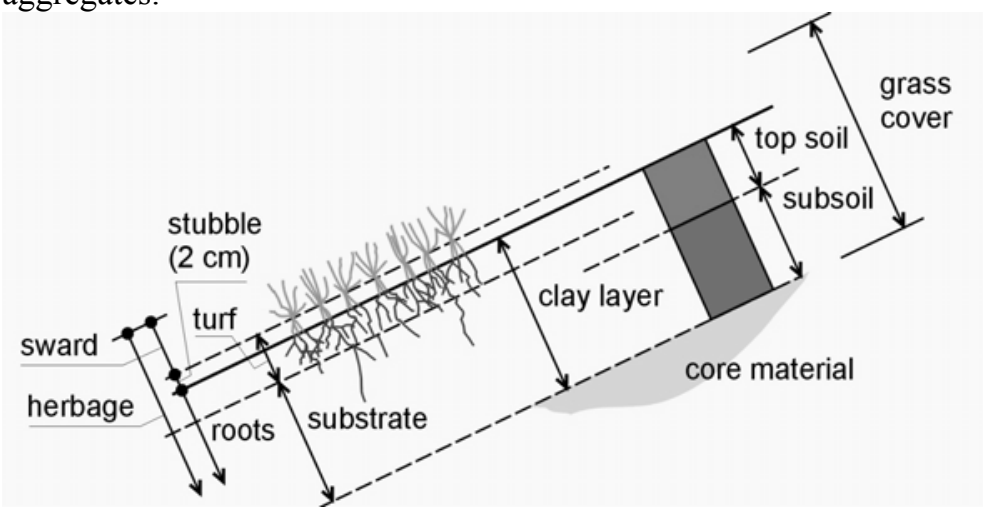

Figure 1. Definition sketch of grass cover (Muijs 1999)

\footnotetext{
${ }^{1}$ Deltares, P.O. Box 177, $2600 \mathrm{MH}$ Delft, The Netherlands

${ }^{2}$ Royal Haskoning, P.O. Box 151, 6500 AD Nijmegen, The Netherlands

${ }^{3}$ Delft University of Technology, P.O.Box 5048, 2600 GA Delft, The Netherlands

${ }^{4}$ Van der Meer Consulting B.V., P.O.Box 423, 8440 AK Heerenveen, The Netherlands
} 
Experiments by Mirtskhoulava $(1988,1991)$ have shown that the erosion of clay with soil structure, in a water-saturated state, occurs in several stages. In the initial stage, elementary dispersed, loosened, aggregates separate. Those with weakened bonds are washed away. This process leads to a rougher surface with increased drag, shear and lift forces on elements with a further increase of flow velocity due to local constriction. Higher pulsating forces increase the vibration and dynamic action on the protruding aggregates. As a result the bonds between aggregates are destroyed gradually, until an aggregate is instantaneously torn out of the surface and carried away by the flow.

The above mentioned erosion process is influenced not only by flow velocity and turbulence but also by the following strength parameters: cohesion, angle of internal friction, Atterbergse limits (plastic and liquid limit), porosity, sand and organic content (Winterwerp 1989).

On the inner slope the sward contributes to the strength of the grass cover by covering the clay aggregates during overtopping, although its contribution is a minor one. Near the surface, the strength is dominated by the root reinforcement, whereas deeper below the surface where the amount of roots decreases rapidly, the cohesion and the internal friction angle of the clay itself determines the strength.

The strength of both clay and grass is discussed in relation to a turf-element model where the second law of Newton is applied to explain the incipient motion of the material of the grass cover. The load is modelled by the uplift force caused by bed pressure fluctuations, whereas the strength is characterized by the self-weight of the soil, cohesion, shear and root stresses.

\section{TURBULENCE}

The grass causes considerable turbulence, energy loss and flow retardance. Though the Manning roughness coefficient is specifically known as a retardance coefficient, the bed roughness can also be expressed by the well-known Chézy coefficient:

$$
U_{0}=C \sqrt{R_{h} S_{b}}
$$

where $C\left[\mathrm{~m}^{0.5} / \mathrm{s}\right]$ is the Chézy coefficient representing the bed turbulence, $R_{h}$ is the hydraulic radius, $S_{b}$ is the energy slope and $U_{0}$ is the depth-averaged flow velocity. The depth-averaged relative turbulence intensity $r_{0}$ is defined as (Hoffmans 1993):

$$
r_{0}=\frac{\sqrt{k_{0}}}{U_{0}} \text { where } k_{0}=\frac{1}{h} \int_{0}^{h} 1 / 2\left(\sigma_{u}^{2}(z)+\sigma_{v}^{2}(z)+\sigma_{w}^{2}(z)\right) \mathrm{d} z
$$

where $h$ is the flow depth, $k_{0}$ is the depth-averaged turbulent kinetic energy and $\sigma_{u}, \sigma_{v}$ and $\sigma_{w}$ are the standard deviation of the fluctuating velocities in $x$ (= longitudinal), $y$ (= transverse) and $z$ (= vertical) directions. For uniform flow 
conditions $k_{0}=\left(c_{0} u *\right)^{2}$ where $c_{0}=1.21$ and $u_{*}$ is the bed shear velocity. Using the Chézy equation, $r_{0}$ for uniform flow reads:

$$
r_{0}=c_{0} \frac{u_{*}}{U_{0}}=c_{0} \frac{\sqrt{g}}{C}
$$

where $g$ is the gravitational acceleration. Prototype experiments on a sea dike near Delfzijl (Akkerman et al. 2007 and Van der Meer 2007) show that on the inner slope with steepness $1 \mathrm{~V}: 2.8 \mathrm{H}$ or $S_{b}=0.36$, the maximum flow velocity reaches a value up to $7 \mathrm{~m} / \mathrm{s}$. Flow depths vary from 0.02 to $0.5 \mathrm{~m}$, resulting in high turbulence intensities (Table 1).

\begin{tabular}{|c|c|c|c|c|c|}
\hline $\begin{array}{c}\text { Wave } \\
\text { overtopping } \\
\text { volume }(1 / \mathrm{m})\end{array}$ & $\begin{array}{c}U_{0} \\
(\mathrm{~m} / \mathrm{s})\end{array}$ & $\begin{array}{c}h \\
(\mathrm{~m})\end{array}$ & $\begin{array}{l}S_{b} \\
(-)\end{array}$ & $\begin{array}{c}C^{(1)} \\
\left(\mathrm{m}^{0.5} / \mathrm{s}\right)\end{array}$ & $\begin{array}{c}r_{0}^{(2)} \\
(-)\end{array}$ \\
\hline 50 & 2.0 to 3.0 & 0.02 & 0.36 & 23.6 to 35.4 & 0.11 to 0.16 \\
\hline 150 & 3.0 to 4.0 & 0.04 & 0.36 & 23.8 to 31.8 & 0.12 to 0.16 \\
\hline 400 & 4.0 to 5.0 & 0.09 & 0.36 & 22.2 to 27.8 & 0.14 to 0.17 \\
\hline 700 & 4.5 to 5.5 & 0.13 & 0.36 & 20.5 to 25.0 & 0.15 to 0.19 \\
\hline 1000 & 5.0 to 6.0 & 0.19 & 0.36 & 19.3 to 23.2 & 0.16 to 0.20 \\
\hline 1500 & 5.5 to 6.5 & 0.26 & 0.36 & 18.0 to 21.2 & 0.18 to 0.21 \\
\hline 2500 & 6.0 to 7.0 & 0.38 & 0.36 & 16.2 to 18.9 & 0.20 to 0.23 \\
\hline 3500 & 6.5 to 7.5 & 0.50 & 0.36 & 15.3 to 17.7 & 0.21 to 0.25 \\
\hline
\end{tabular}

\section{MOHR COULOMB}

The Mohr Coulomb criterion describes soil failure in terms of shear stress and effective normal stress along an assumed sliding plane as follows (e.g. Lambe and Whitman 1969):

$$
\tau=c^{\prime}+\left(\sigma-p_{w}\right) \tan \phi^{\prime}
$$

where $c^{\prime}$ is the effective cohesion, $p_{w}$ is the pore water pressure, $\sigma$ is the soil normal stress, $\tau$ is the shear strength (obtained from the shear stress that can be mobilized between soil particles) and $\phi^{\prime}$ is the effective internal friction angle. Cohesion is the result of cementation, electrical bonding of clays and organic colloids and capillary tension, whereas $\phi^{\prime}$ represents the frictional interaction of individual particles and the interlocking of particles. The effective normal stress is caused by the soil weight and by the pore water pressure.

\section{Root reinforcement of soil}

Typically the strength of roots is modelled by an artificial cohesion $\left(c_{r}\right)$ (e.g. O'Loughin and Ziemer 1982). In a root permeated soil Eq. 4 can be modified to include $c_{r}$ :

$$
\tau=c^{\prime}+c_{r}+\left(\sigma-p_{w}\right) \tan \phi^{\prime}
$$


Most attempts to determine the effects of root reinforcement by grassland vegetation have used root-cohesion values estimated using the root equation of Wu et al. (1979), which requires the root tensile stress $\left(t_{r}\right)$, the root diameter $\left(d_{r}\right)$ and the angle of shear deformation $(\theta)$. Where a root crosses a shear zone the root tensile stress can be resolved into components perpendicular $\left(\sigma_{r}\right)$ and parallel $\left(T_{r}\right)$ to the shear zone (Fig. 2). The artificial root cohesion $\left(c_{r}\right)$ and the normal grass strength $\left(\sigma_{g}\right)$ give:

$$
\begin{gathered}
c_{r}=t_{r} \frac{A_{r}}{A}(\cos \theta \tan \phi+\sin \theta) \text { with } T_{r}=t_{r} \sin \theta \text { and } \sigma_{r}=t_{r} \cos \theta \\
\sigma_{g}=t_{r} \frac{A_{r}}{A} \cos \theta
\end{gathered}
$$

where $A_{r} / A$ is the root area ratio also known as RAR and $\theta$ is the angle of shear rotation. Although little is known about $\theta$, from field observations of conifers Wu et al. (1979) suggested a range of $45^{\circ}$ to $70^{\circ}$. Since, the term $(\cos \theta \tan \phi+$ $\sin \theta$ ) in Eq. 6 is insensitive to changes in $\theta$, it is close to 1.2 for a large range of $\theta$ values, so the root cohesion may be rewritten as:

$$
c_{r}=1.2 t_{r} \frac{A_{r}}{A}
$$

This static root model assumes that all roots break, and that they all break simultaneously. However, prototype and laboratory experiments have shown that the roots do not all break simultaneously (e.g. Pollen and Simon 2003). Therefore, Eqs. 6,7 and 8 probably overestimate $c_{r}$ and $\sigma_{g}$.

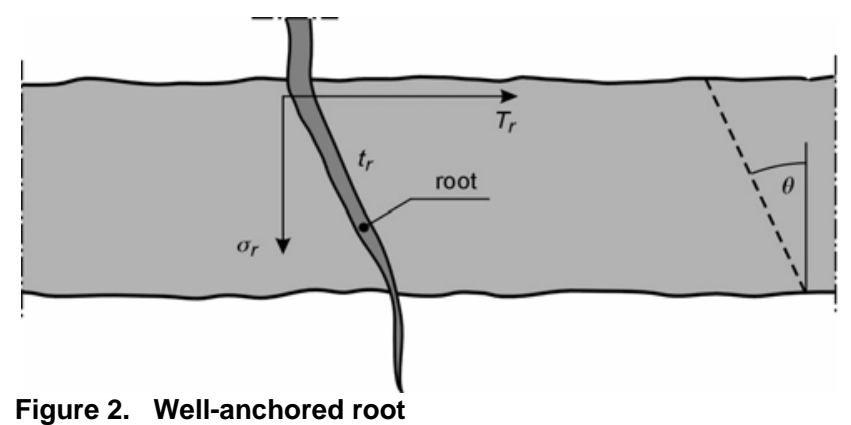

\section{Root tensile stress}

The root tensile stress $\left(t_{r}\right)$ depends strongly on the type and the quality of grass. Table 2 shows indicative values of $t_{r}$ for different grasses, with no correlation for size, age or season. Sprangers (1999) measured grass parameters such as the root length, root diameter and the dry root mass densities from 24 Dutch dike sites. He found that the root area of dike grassland decreases exponentially with depth. About $50 \%$ of the roots were found in the top $6 \mathrm{~cm}$ of the turf and about $75 \%$ of the roots were within the top $20 \mathrm{~cm}$. Based on 
Sprangers work, the Dutch guidelines for the safety assessment of primary dikes (VTV 2006) distinguishes 4 different qualities for the grass cover namely, very poor, poor, average and good, where the quality of the grass is strongly correlated to the root area ratio (Fig. 3). The average root diameter of Dutch grasses is about $d_{r}=0.13 \mathrm{~mm}$, which is significantly smaller than the range of root diameters tested by the Chinese researchers Chengh et al. 2003. If the following assumptions are made: $d_{r}=0.13 \mathrm{~mm}, t_{r}=20 \cdot 10^{6} \mathrm{~N} / \mathrm{m}^{2}, \theta=45^{\circ}$ and $\phi$ $=35^{\circ}$, then the ranges of $c_{r}$ and $\sigma_{g}$ can be determined for different qualities of Dutch grass (Table 3 ).

\section{TURF-ELEMENT MODEL}

If a grass-clay aggregate on a horizontal plane with dimensions of an element $\left(=\ell_{x} \ell_{y} \ell_{z}=d^{3}\right.$ where $\ell_{x}, \ell_{y}$ and $\ell_{z}$ are length scales in the $x, y$ and $z$ direction respectively and $d$ is the mean particle diameter or the representative aggregate diameter), is considered, the following forces acting on this element can be distinguished: the vertical force $\left(F_{p}\right)$ caused by pressure fluctuations above and underneath the aggregate, the weight $\left(F_{w}\right)$, and the forces by shear, cohesion and the roots of grass (Fig. 4).

\begin{tabular}{|c|c|c|}
\hline Type of grass & $d_{r}(\mathrm{~mm})$ & $t_{r}\left(\times 10^{6} \mathrm{~N} / \mathrm{m}^{2}\right)$ \\
\hline Late Juncellus sp. & $0.38 \pm 0.43$ & $24.50 \pm 4.20$ \\
\hline Dallis grass & $0.92 \pm 0.28$ & $19.74 \pm 3.00$ \\
\hline White Clover & $0.91 \pm 0.11$ & $24.64 \pm 3.36$ \\
\hline Vetiver & $0.66 \pm 0.32$ & $85.10 \pm 31.2$ \\
\hline Common Cetipede grass & $0.66 \pm 0.05$ & $27.30 \pm 1.74$ \\
\hline Bahio grass & $0.73 \pm 0.07$ & $19.23 \pm 3.59$ \\
\hline Manila grass & $0.77 \pm 0.67$ & $17.55 \pm 2.85$ \\
\hline Bermuda grass & $0.99 \pm 0.17$ & $13.45 \pm 2.18$ \\
\hline
\end{tabular}

\begin{tabular}{|c|c|c|c|c|c|c|c|}
\hline $\begin{array}{l}A_{r} / A \\
(\%)\end{array}$ & $\begin{array}{c}A_{r} / A \\
\left(\mathrm{~mm}^{2} / \mathrm{m}^{2}\right)\end{array}$ & $\begin{array}{l}\text { Number } \\
\text { of roots } \\
\text { No. } / \mathrm{m}^{2}\end{array}$ & $\begin{array}{c}\text { Quality } \\
\text { grass } \\
\text { acc.to VTV }\end{array}$ & \begin{tabular}{|c|} 
Turf area \\
per root \\
$\left(\mathrm{mm}^{2)}\right)$
\end{tabular} & $\begin{array}{c}\text { Root }^{(3)} \\
\text { spacing } \\
(\mathrm{mm})\end{array}$ & $\begin{array}{c}c_{r}^{(4)} \\
\left(\mathrm{kN} / \mathrm{m}^{2}\right)\end{array}$ & $\begin{array}{c}\sigma_{g}{ }^{(5)} \\
\left(\mathrm{kN} / \mathrm{m}^{2}\right)\end{array}$ \\
\hline 0.02 & 200 & 15100 & very poor & 66 & 8 & 4.8 & 2.8 \\
\hline 0.04 & 400 & 30150 & poor & 33 & 6 & 9.6 & 5.6 \\
\hline 0.06 & 600 & 45200 & average & 22 & 5 & 14.4 & 8.4 \\
\hline 0.08 & 800 & 60300 & good & 17 & 4 & 19.2 & 11.2 \\
\hline \multicolumn{4}{|c|}{$\begin{array}{l}\text { (1) No. }=A_{r} / A_{1 \text { root }} \text { where } A_{1 \text { root }}=1 / 4 \pi d_{r}^{2} \text { and } \\
d_{r}=0.13 \mathrm{~mm} \text {, } \\
\text { (2) Turf area per root }=A / \mathrm{No} .\left(A=1 \mathrm{~m}^{2}\right) \text {, } \\
\text { (3) Root spacing }=(A / \mathrm{No} .)^{1 / 2}\end{array}$} & \multicolumn{4}{|c|}{$\begin{array}{l}{ }^{(4)} c_{r}=1.2 t_{r}\left(A_{r} / A\right) \text { (see Eq. } 6 \text { with } \theta=45^{0}, \\
\left.\phi=35^{\circ} \text { and } t_{r}=20 \cdot 10^{6} \mathrm{~N} / \mathrm{m}^{2}\right) \\
\text { (5) } \\
\left.\sigma_{g}=0.7 t_{r}\left(A_{r} / A\right) \text { (see Eq. } 7\right)\end{array}$} \\
\hline
\end{tabular}




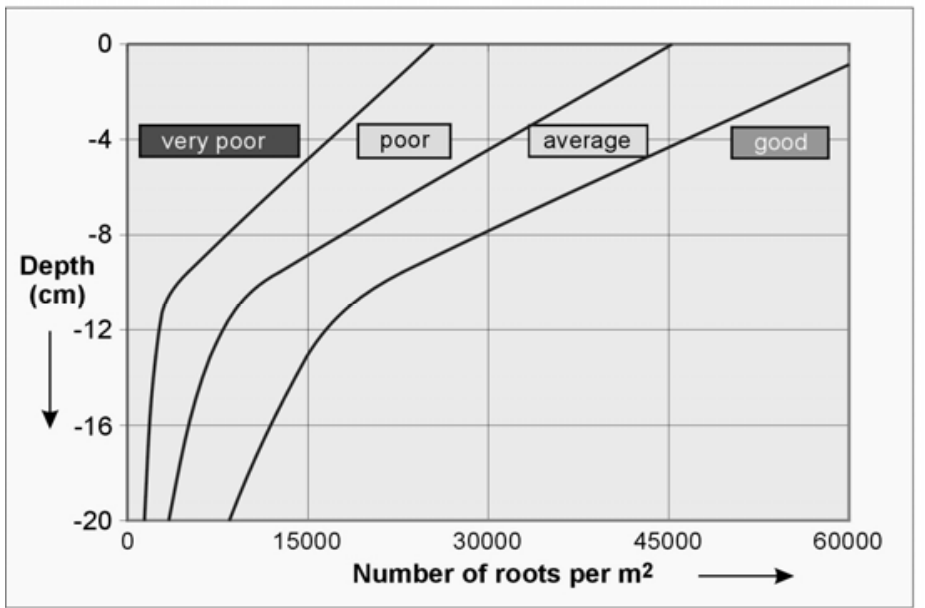

Figure 3. Classification of grass according to the Dutch guidelines for primary defences (VTV 2006)

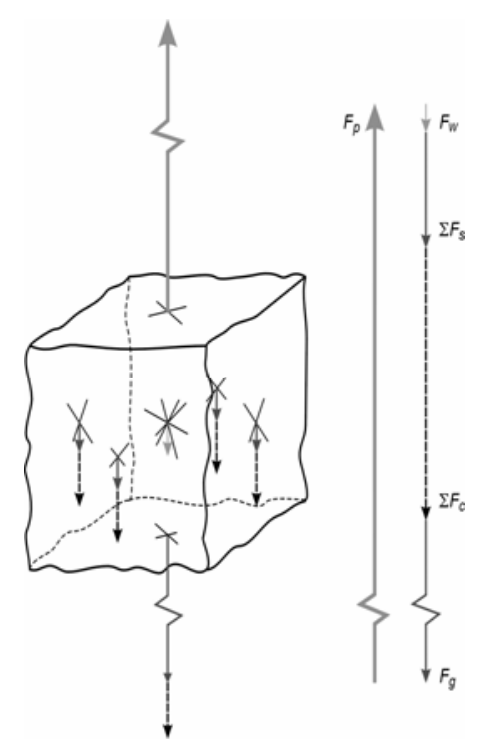

Figure 4. Forces acting upon a turf-element

Incipient motion of a grass-clay aggregate occurs, if the load is larger than the strength, thus:

$$
F_{p} \geq F_{w}+\Sigma F_{s}+\Sigma F_{c}+F_{g}
$$

where $\Sigma F_{s}$ is the sum of the shear forces which act on the four side walls, $\Sigma F_{c}$ is the sum of the cohesion forces acting on both the four side walls and the under side and $F_{g}$ is the grass force (see Eq. 7). Equation 9 can also be given by: 


$$
\begin{aligned}
& p \ell_{x} \ell_{y} \geq\left(\rho_{s}-\rho\right) g \ell_{x} \ell_{y} \ell_{z}+2 f \frac{1}{2}\left(\rho_{s}-\rho\right) g\left(\ell_{x}+\ell_{y}\right)\left(\ell_{z}\right)^{2}+ \\
& +2 c_{s}\left(\ell_{x}+\ell_{y}\right) \ell_{z}+c_{s} \ell_{x} \ell_{y}+\sigma_{g} \ell_{x} \ell_{y}
\end{aligned}
$$

where $c_{s}$ is a characteristic cohesion, $f(=\tan \phi)$ is a friction factor, $p$ represents the pressure fluctuation, $\rho$ is the fluid density and $\rho_{s}$ is the material density. Note that in the turf-element model the force of the inward or outward groundwater flow can easily be included. Assuming that $\ell_{x}=\ell_{y}=\ell_{z}=d$, Eq. 10 becomes:

$$
p \geq(1+2 f)\left(\rho_{s}-\rho\right) g d+5 c_{s}+\sigma_{g}
$$

If the clay aggregate is only fixed at the bottom owing to vertical fissures around the aggregate, thus if the shear and cohesion forces on the clay aggregate do not act on the four sidewalls, there is only cohesion at the bottom, the shear stresses reduce to zero and the cohesion decreases by a factor 5 :

$$
p \geq\left(\rho_{s}-\rho\right) g d+c_{s}+\sigma_{g}
$$

Emmerling (1973) investigated the instantaneous structure of the pressure near the bed under turbulent flow conditions. He found that the standard deviation of the instantaneous pressure $\left(\sigma_{p}\right)$ on the bed is about three times the mean bed shear stress $\left(\tau_{0}\right)$ and that the maximum pressure (maximum underflow or maximum overflow) could be up to $6 \sigma_{p}$. With estimates of $p_{\max } / \sigma_{p}=6$ and $\sigma_{p}$ $=3 \tau_{0}$, the maximum pressure peaks can reach up to $p_{\max }=18 \tau_{0}$. The critical condition of lifting the grass-clay aggregate is reached if $p=p_{\max }$ and if $\tau_{0}$ equals the critical mean bed shear stress $\left(\tau_{c}\right)$, thus:

$$
\tau_{c}=\alpha_{\tau}\left(\left(\rho_{s}-\rho\right) g d+c_{s}+\sigma_{g}\right) \text { with } \quad \alpha_{\tau}=1 / 18=0.056
$$

If there is neither cohesion $\left(c_{s}=0\right)$ nor grass $\left(\sigma_{g}=0\right), \tau_{c}$ of loosely packed material is:

$$
\tau_{c}=\Psi_{c}\left(\rho_{s}-\rho\right) g d \quad \text { with } \Psi_{c}=\alpha_{\tau}
$$

In turbulent flow the critical Shields parameter $\Psi_{c}$ varies from 0.03 to 0.06 for coarse sand and gravel, whereas for small Reynolds numbers to fully laminar flow $\Psi_{c}$ increases from 0.01 to 0.2 . Hence, the first term in Eq. 13 confirms the earlier research activities of Shields. Subsequently, the magnitude of the second and third terms $\left(c_{s}\right.$ and $\left.\sigma_{g}\right)$ are further analysed using the equations of Mirtskhoulava and Partheniades and the $C_{E}$-method of Verheij et al. (1995). $\tau_{0}$, defined as $\tau_{0}=\rho(u *)^{2}$, reads using Eq. 3:

$$
\tau_{0}=\frac{1}{c_{0}^{2}} \rho\left(r_{0} U_{0}\right)^{2}=0.7 \rho\left(r_{0} U_{0}\right)^{2}
$$

Combining Eqs. 13 and 15 and assuming that the flow is hydraulically rough, thus $r_{0}>0.05$ and $U_{0}=U_{c}$ the critical depth-averaged flow velocity is: 


$$
U_{c}=\frac{\alpha_{0}}{r_{0}} \sqrt{\Delta g d+\frac{c_{s}}{\rho}+\frac{\sigma_{g}}{\rho}} \quad \text { with } \quad \alpha_{0}=\sqrt{\alpha_{\tau} c_{0}^{2}}=0.29
$$

where $\Delta\left(=\left(\rho_{s}-\rho\right) / \rho\right)$ is the relative density. When the bed becomes rougher or the bed turbulence increases, $U_{c}$ decreases. $U_{c}$ represents the mean velocity that will not cause erosion. Although this velocity is uncertain it can be approximated with experience and expert judgement. If $U_{0}$ above a clayey bed is lower than $U_{c}$, the cohesive bed is assumed to be stable. Based on the work of (Mirtskhoulava 1988, 1991), Hoffmans and Verheij (1997) simplified the expression for cohesive sediments:

$$
U_{c}=\log \left(\frac{8.8 h}{d_{a}}\right) \sqrt{\frac{0.4}{\rho}\left[\left(\rho_{s}-\rho\right) g d_{a}+0.6 C_{f}\right]}
$$

in which $C_{f}(=0.035 c)$ is the fatigue rupture strength of clay, $c$ is the cohesion and $d_{\mathrm{a}}(=0.004 \mathrm{~m})$ is the size of detaching aggregates according to Mirtskhoulava. Using the relation between turbulence and bed roughness (Eq. 3), Eq. 17 becomes:

$$
U_{c}=\frac{\alpha_{M, 1}}{r_{0}} \sqrt{\Delta g d_{a}+\frac{0.6 C_{f}}{\rho}} \text { with } \alpha_{M, 1}=0.13
$$

Consequently, Eqs. 16 and 18 are similar. However, there are differences between the definitions of the cohesion: $c_{s}$ and $C_{f}$, the representative aggregate diameter: $d$ and $d_{a}$ and the critical Shields parameter: $\Psi_{c}$ and $\Psi_{c, M}$ respectively. In addition, the turf-element model includes the strength of grass. Assuming no cohesion and $d=d_{a}$, Eq. 18 can be rewritten as:

$$
\tau_{c}=\Psi_{c, M}\left(\rho_{s}-\rho\right) g d \text { with } \Psi_{c, M}=\frac{0.4 \kappa^{2}}{2.3^{2}}=0.012
$$

in which $\kappa(=0.4)$ is the constant of Von Kármán whence follows that the Russian design relation is very conservative. Aggregate particles with $d=4 \mathrm{~mm}$ will frequently move if the Shields parameter is 0.056 (see also Eq. 14). If $\Psi_{c, M}$ $=0.012$ there is hardly movement of particles.

According to Partheniades (1965) the relation for the erosion rate of cohesive soils is:

$$
E=\frac{\mathrm{d} m}{\mathrm{~d} t}=\frac{M}{\tau_{c}}\left(\tau_{0}-\tau_{c}\right)
$$

where $E$ is the erosion rate (mass) per unit area of the bed, $m\left[\mathrm{~kg} / \mathrm{m}^{2}\right]$ is the mass of sediment on the bed, $M\left(=0.00001\right.$ to $\left.0.0005 \mathrm{~kg} /\left(\mathrm{m}^{2} \mathrm{~s}\right)\right)$ is a coefficient that depends on sediment characteristics and $t$ is the time. To investigate the erodibility of embankments with a grass cover under wave conditions experiments were conducted in the Scheldt basin (Verheij et al. 1995) and Delta 
flume (Meijer and Verheij 1998). According to Verheij et al. (1995) the measure of erosion of clay and grass is represented by an overall strength parameter $C_{E}$ $\left[\mathrm{m}^{-1} \mathrm{~s}^{-1}\right]$ which is inversely proportional to $\tau_{c}$. Based on dimensional considerations $C_{E}$ is here rewritten as:

$$
\frac{M}{\tau_{c}} \equiv C_{E} \quad \text { with } \quad C_{E}=\alpha_{E} \frac{g^{2} d_{a}}{v U_{c}^{2}}
$$

where $\alpha_{E}\left(=10^{-10}\right)$ is a coefficient and $v$ is the kinematic viscosity. Table 4 summarizes characteristic values of $C_{E}$ and $U_{c}$ for clay and grass. For clay four classes are defined namely poor, structured, good and very good. The influence of both the shear forces and the self-weight on the strength of clay decreases significantly as the cohesion increases. In other words for large values of $c_{s}$ the strength of clay is determined only by cohesion. The same applies to the strength of grass, which is largely determined by $\sigma_{g}$.

The Dutch dikes are covered with either very soft clay (where $0<c<12$ $\mathrm{kN} / \mathrm{m}^{2}$ or $\left.0<c_{s}<0.25 \mathrm{kN} / \mathrm{m}^{2}\right)$ or soft clay $\left(12<c<24 \mathrm{kN} / \mathrm{m}^{2}\right.$ or $0.25<c_{s}<$ $0.50 \mathrm{kN} / \mathrm{m}^{2}$ ). Even though the classification for clay defined by Verheij et al. (1995) is in agreement with typical Dutch situations, this does not yield any information about the actual strength of the clay layer or the exact relations between $C_{E}, c_{s}$ and $U_{c}$. According to Mirtskhoulava (1991) the ratio between the mean and characteristic values of the cohesion is about 50, which is certainly adequate for design purposes. Within the scope of testing Dutch primary defences it is recommended to determine an adequate value for $c_{s}$, also including different parameters for the influence of the qualities of clay, for example the clay, silt and sand percentages, effect of different clay minerals, the effect of the organic contents, the shrink and swell behaviour of the clay, the physicalchemical characteristics, temperature, salt percentage of pore water (de Vroeg et al. 2002).

$\sigma_{g}$ as given in Table 4 is assumed to vary from 2.8 to $11.2 \mathrm{kN} / \mathrm{m}^{2}$ and represents the range of very poor to good grass. The normal grass strength is influenced by the root area ratio, the root diameter $\left(d_{r}=0.13 \mathrm{~mm}\right)$, the maximum root tensile stress $\left(t_{r}=20 \cdot 10^{6} \mathrm{~N} / \mathrm{m}^{2}\right)$ and the deformation angle. Since these parameters can easily be determined to a reasonable degree of precision, the computed value of $\sigma_{g}$ must also be accurate. Despite the fact that the modelling is based on physical considerations and should be representative for the strength of the grass cover, it should be noted that the model does not include the effects of more than one root. Therefore, it is necessary to examine the deformation of grass as function of the dynamic load, i.e. the relation between $\sigma_{g}$ and $U_{c}$ for grass, more in detail and to validate the incipient motion of clay and grass by carrying out sufficient experiments. 


\begin{tabular}{|c|c|c|c|c|}
\hline CLAY & \multicolumn{2}{|c|}{$C_{E}$-method } & \multicolumn{2}{|c|}{ Turf-element model } \\
\hline $\begin{array}{l}\text { Quality of clay } \\
\text { (Verheij et al. } \\
\text { 1995) }\end{array}$ & $\begin{array}{c}C_{E} \\
{\left[\mathrm{~m}^{-1} \mathrm{~s}^{-1}\right]}\end{array}$ & $\begin{array}{c}U_{c}^{(1)} \\
{[\mathrm{m} / \mathrm{s}]}\end{array}$ & $\begin{array}{c}C_{s}^{(2)} \\
{\left[\mathrm{kN} / \mathrm{m}^{2}\right]}\end{array}$ & $\begin{array}{c}U_{c}^{(3)} \\
{[\mathrm{m} / \mathrm{s}]}\end{array}$ \\
\hline $\begin{array}{l}\text { sand } \\
\text { poor } \\
\text { structured } \\
\text { good } \\
\text { very good }\end{array}$ & $\begin{array}{l}17.1 \cdot 10^{-4} \\
4.3 \cdot 10^{-4} \\
1.1 \cdot 10^{-4} \\
0.60 \cdot 10^{-4} \\
0.32 \cdot 10^{-4}\end{array}$ & $\begin{array}{l}0.15 \\
0.3 \\
0.6 \\
0.8 \\
1.1\end{array}$ & $\begin{array}{l}0.00 \\
0.11 \\
0.25 \\
0.50\end{array}$ & $\begin{array}{l}0.3 \\
0.6 \\
0.8 \\
1.1\end{array}$ \\
\hline \multicolumn{5}{|c|}{$\begin{array}{l}\text { (1) computed using Eq. } 21 \text {, } \\
\text { (2) } c_{s}=0.6 C_{f}=0.6 \cdot 0.035 c=0.021 c\left(\text { or } c \approx 50 c_{s}\right) \text {, } \\
\text { computed using Eq. } 16 \text { with } d=d_{a}=0.004 \mathrm{~m}, r_{0}=0.2, \sigma_{g}=0 \text {. }\end{array}$} \\
\hline GRASS & \multicolumn{2}{|c|}{$C_{E}$-method } & \multicolumn{2}{|c|}{ Turf-element model } \\
\hline $\begin{array}{r}\text { Quality of grass } \\
\text { (VTV 2006) }\end{array}$ & $\begin{array}{c}C_{E} \\
{\left[\mathrm{~m}^{-1} \mathrm{~s}^{-1}\right]}\end{array}$ & $\begin{array}{l}U_{c}{ }^{(1)} \\
{[\mathrm{m} / \mathrm{s}]}\end{array}$ & $\begin{array}{c}\sigma_{g} \\
{\left[\mathrm{kN} / \mathrm{m}^{2}\right]}\end{array}$ & $\begin{array}{l}U_{c}^{(4)} \\
{[\mathrm{m} / \mathrm{s}]}\end{array}$ \\
\hline $\begin{array}{l}\text { very poor } \\
\text { poor } \\
\text { averaged } \\
\text { good }\end{array}$ & $\begin{array}{l}0.062 \cdot 10^{-4} \\
0.033 \cdot 10^{-4} \\
0.022 \cdot 10^{-4} \\
0.016 \cdot 10^{-4}\end{array}$ & $\begin{array}{l}2.5 \\
3.4 \\
4.2 \\
4.9\end{array}$ & $\begin{array}{c}2.8 \\
5.6 \\
8.4 \\
11.2\end{array}$ & $\begin{array}{l}2.5 \\
3.4 \\
4.2 \\
4.9\end{array}$ \\
\hline
\end{tabular}

\section{SCOURING MODEL}

In the framework of the Dutch Delta works systematic research was carried out to examine both the incipient motion of loosely packed materials and the local scour process downstream of hydraulic sills. The Breusers time-dependent scour equation gives (e.g. Hoffmans and Verheij 1997):

$$
\frac{y_{m}}{\lambda}=\left(\frac{t}{t_{1}}\right)^{\gamma} \quad \text { with } \quad t_{1}=\frac{K_{330} \lambda^{2} \Delta^{1.7}}{\left(\alpha U_{0}-U_{c}\right)^{\beta}}
$$

in which $K_{330}$ is a dimensional coefficient, $t_{1}$ is the characteristic time at which $y_{m}=\lambda, y_{m}$ is the scour or erosion depth, $\alpha\left(=1.5+5 r_{0}\right)$ is the turbulence coefficient, $\beta=4.3$ for loosely packed materials, $\gamma$ is a coefficient and $\lambda$ is a characteristic length scale in the vertical direction.

For loosely packed materials $\beta$ varies from 4 to 6 , whereas for cohesive sediments $\beta=2$ (see also Eq. 20). Van der Meulen and Vinjé (1975) showed that $\gamma$ strongly depends on the degree of turbulence and lies in the range of $\gamma=$ 0.4 for $2 \mathrm{D}$ flow to $\gamma=0.8$ for 3D flow. To simulate the erosion of grass under highly turbulent flow conditions, and assuming that $\beta=2$ and $\gamma=1.0$, Eq. 22 becomes, see also Van den Bos (2006) who developed the EP Model (in Dutch: Erosiegevoelige Plekken methode) or "spots susceptible to erosion" model for inner dike slopes covered with grass:

$$
y_{m}=\left(E_{\text {soil }}\right)^{-1}\left(\alpha U_{0}-U_{c}\right)^{2} t
$$

where $E_{\text {soil }}=15 \cdot 10^{6}[\mathrm{~m} / \mathrm{s}]$ is a soil parameter depending on $\lambda, \Delta$ and other parameters that determine the qualities of both grass and clay which is calibrated 
using only one prototype experiment. Combining Eqs. 20, 21 and 23 and assuming that $\left(U_{0}^{2}-U_{c}^{2}\right) \approx\left(\alpha U_{0}-U_{c}\right)^{2}$ gives:

$$
E_{\text {soil }} \equiv \rho_{s} U_{c}^{2}(M)^{-1} \equiv\left(C_{E}\right)^{-1}
$$

If the grass cover fails that is if $y_{m}$ is assumed to be greater than $0.1 \mathrm{~m}$, Eq. 23 simplifies to:

$$
U_{0}=\frac{1}{\alpha}\left(\sqrt{0.1 E_{\text {soil }} / t}+U_{c}\right)
$$

Figure 5 shows three grass curves representing $U_{c}=5 \mathrm{~m} / \mathrm{s}$ (with $E_{\text {soil }}=10 \cdot 10^{6}$ $\mathrm{m} / \mathrm{s}), U_{c}=3 \mathrm{~m} / \mathrm{s}$ (with $E_{\text {soil }}=5 \cdot 10^{6} \mathrm{~m} / \mathrm{s}$ ) and $U_{c}=2 \mathrm{~m} / \mathrm{s}$ (with $E_{\text {soil }}=2.5 \cdot 10^{6} \mathrm{~m} / \mathrm{s}$ ) for steady flow conditions, which are nearly in agreement with the stability curves from CIRIA (Hewlett et al. 1987). The curves should be considered as indicative and could be used to explain the physical process close to the bed and to refine definitions.

During storm conditions the overtopping discharge varies in time. Considering all waves during a storm the scour depth as function of time can be rewritten as:

$$
y_{m}=\sum_{i=1}^{i=n} \frac{\left(0.7 \alpha U_{m}-U_{c}\right)^{2}}{E_{\text {soil }}} t_{\text {wave }}
$$

where $n$ is the number of waves, $U_{m}$ is the maximum flow velocity per overtopping event and $t_{\text {wave }}$ is the wave overtopping time.

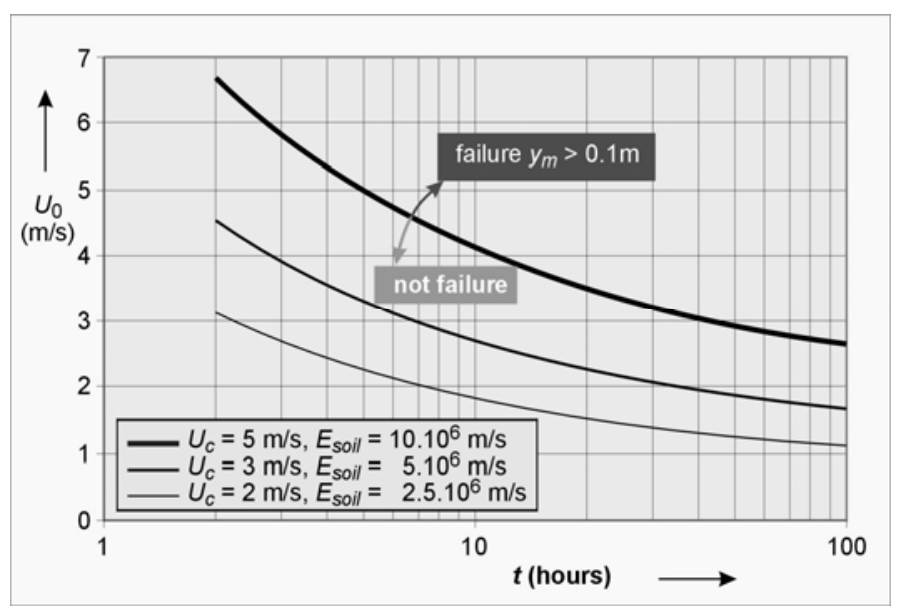

Figure 5. $U_{0}$ as function of time obtained from Eq. 25 using $r_{0}=0.2, y_{m}=0.1 \mathrm{~m}$; grass cover fails if $y_{m}>0.1 \mathrm{~m}$ 


\section{CONCLUSIONS AND RECOMMENDATIONS}

The turf-element model should be considered as a conceptual model in which the physics are described well at a macroscopic level. To be able to update the present Dutch guidelines for the safety assessment of primary dikes (VTV 2006) in 2011, it is necessary to examine the deformation of grass as function of the load and to understand the physical meaning of the soil parameter $E_{\text {soil }}$ for different types of grass and clay.

Equation 23 is based on accepted scour relations deduced from the Dutch systematic scour research carried out in the 1960s (e.g. Hoffmans and Verheij 1997) and enables us to find adequate definitions for the failure mechanism of the erodibility of the grass and clay cover.

Although air content and turbulence intensities were not measured in the flow on the inner slope during wave overtopping events, it can be concluded that $r_{0}$ is significantly higher than the usual turbulence level corresponding to uniform flow conditions in e.g. rivers. Therefore, it is recommended that in the next prototype experiments flow velocities in the three flow directions should be measured. Moreover, it is also necessary to measure the air content in the flow to analyze the influence of air on the erodibility of grass.

\section{REFERENCES}

Akkerman, G.J, Gerven, van, K.A.J., Schaap, H.A., and, Meer, van der, J.W. 2007. Workpackage 3: Development of alternative overtopping-resistantsea defences, Phase 3: wave overtopping erosion tests at Groningen sea dyke,

Rijkswaterstaat, Delft.

Bos, van den, W., 2006. Erodibility of a grass revetment during wave overtopping (in Dutch), MSc. Thesis, Technical University Delft, Delft

Cheng, H., Yang, X., Liu, A., Fu, H., Wan, M., 2003. A study on the performance and mechanism of soil-reinforcement by herb root system. Proc. of the $3^{\text {rd }}$ Int. Conf. on Vetiver and Exhibition, Guangzhou, China.

Emmerling, A., 1973. Die momentane Struktur des Wanddruckes einer turbulenten Grenzschichtströmung, Max-Planck-Institut für Strömungsforschung, Bericht 9.

Hewlett, H.W.M., Boorman, L.A., and M.E. Bramley, 1987. Design of Reinforced Grass Waterways, Construction Industry Research and Information Association, Rep. No.116, London.

Hoffmans, G.J.C.M., 1993. A study concerning the influence of the relative turbulence intensity on local-scour holes, Rijkswaterstaat, Delft.

Hoffmans, G.J.C.M. and Verheij, H.J., 1997. Scour manual, Balkema, Rotterdam.

Lambe, T.W., and Whitman, R.V., 1969. Soil Mechanics. John Wiley, New York.

O'Loughlin, C., and Ziemer, R.B., 1982. The importance of root strength and deterioration rates upon edaphic stability in steepland forest. Proc. of 
I.U.F.R.O. Workshop P.1.07-00 Ecology of Subalpine Ecosystems as a Key to Management. Oregon State University, Corvallis, Oregon. 70-78.

Meer, van der, J.W., 2007. Workpackage 3: Development of alternative overtopping-resistant sea defences, Phase 3: Design, construction, calibration and use of the wave overtopping simulator, Rijkswaterstaat, Delft.

Meijer, D.G. and Verheij, H.J., 1998. Grassed dikes (in Dutch), Rep. Q1878, Deltares, Delft.

Meulen van der, T., and Vinjé, J.J., 1975. Three-dimensional local scour innoncohesive sediments, Proc. 16 ${ }^{\text {th }}$ IAHR-congress, Sao Paulo, Brasil (also Deltares, Delft, Publication 180).

Mirtskhoulava, Ts. Ye., 1988. Basic physics and mechanics of channel erosion, Gidrometeoizdat, Leningrad, Russia.

Mirtskhoulava, Ts. Ye., 1991. Scouring by flowing water of cohesive and non cohesive beds, JHR, 29(3), 341-354.

Muijs, J.A., 1999. Grass cover as a dike revetment, Translation of TAWbrochure "Grasmat als Dijkbekleding", Rijkswaterstaat, Delft.

Partheniades, E. (1965). Erosion and deposition of cohesive soils. J. of Hydr. Div., ASCE, 91(HY1).

Pollen, N.L. and Simon, A., 2003. A new Approach for Quantifying RootReinforcement of Streambanks: the RipRoot, American Geophysical Union, Fall Meeting 2003, abstract \#H52A-1174.

Sprangers, J.T.C.M., 1999. Vegetation dynamics and erosion resistance of sea dyke grassland, Doctoral thesis, Wageningen Agriculture University, Wageningen.

Verheij, H.J. (edt.), 1995. Investigation of the strength of a grass cover upon river dikes (in Dutch), Rep. Q1878, Deltares, Delft.

Vroeg, de, J.H., Kruse, G.A.M. and Gent, van M.R.A., 2002. Processes related to breaching of dikes, Erosion due to overtopping and overflow. Deltares, Delft.

VTV, 2006. Safety assessment of the primary flood defences (in Dutch), Ministry

of Transport, Public Works and Water Management, Rijkswaterstaat, Delft.

Winterwerp, J.C., 1989. Cohesive sediments, Flow induced erosion of cohesive beds, Rijkswaterstaat/Deltares, Delft.

Wu, T.H., McKinnell, W.P. III and Swanston, D.N., 1979. Strength of tree roots and landslides on Prince of Wales Island, Alaska. Canadian $J$. of Geotechnical Res. 16(1), 19-33. 